\title{
Płuczki mrówczanowe z dodatkiem niskocząsteczkowej poliwinyloaminy jako alternatywny rodzaj płuczek do dowiercania złóż węglowodorów
}

\section{Formate-based drilling fluids with the addition of low-molecular-weight polyvinylamine as an alternative drill-in fluid system}

\author{
Maciej Stec ${ }^{1}$, Sławomir Wysocki ${ }^{2}$ \\ ${ }^{1}$ Exalo Drilling S.A. \\ ${ }^{2}$ A GH Akademia Górniczo-Hutnicza im St. Staszica w Krakowie
}

\begin{abstract}
STRESZCZENIE: Udostępnienie złoża jest jedną z najważniejszych operacji w trakcie wiercenia otworu wiertniczego, dlatego należy dołożyć starań, aby oddziaływanie wszelkich czynników zewnętrznych na złoże w czasie dowiercania było jak najmniejsze. Znane są różne mechanizmy prowadzące do uszkodzenia strefy przyotworowej. Wśród nich wymienić należy oddziaływania mechaniczne, biologiczne, termiczne, ale również fizykochemiczne, w tym negatywny wpływ płynu wiertniczego, filtratu i jego komponentów. Aby zminimalizować szkodliwe działanie płynu na przepuszczalność skały, do dowiercania używa się płuczek typu drill-in fluid. Nowoczesny przemysł naftowy dysponuje szeregiem rozwiązań koncepcyjnych z zakresu technologii płynów wiertniczych służących do dowiercania. Istnieje możliwość dostosowania składu i parametrów płynu w zależności od charakterystyki warunków geologicznych panujących w otworze. Artykuł przedstawia wyniki badań parametrów technologicznych nowo opracowanej płuczki mrówczanowej z dodatkiem niskocząsteczkowej poliwinyloaminy. Prace nad zsyntezowaniem polimeru prowadzono w laboratorium Katedry Wiertnictwa Wydziału Wiertnictwa, Nafty i Gazu na Akademii Górniczo-Hutniczej w Krakowie. Na bazie poliwinyloaminy i mrówczanu potasu zaprojektowano recepturę płynu, który jest alternatywą dla typowej płuczki mrówczanowej. Na opracowanej płuczce przeprowadzono szereg testów polegających na zbadaniu właściwości reologicznych, filtracyjnych oraz inhibicyjnych, a także wpływu na uszkodzenie strefy przyotworowej. Badania pokazały, że oprócz dobrych właściwości fizykochemicznych opracowana płuczka zapewnia skuteczną ochronę złoża. Dzięki wspólnemu działaniu soli mrówczanowej i poliwinyloaminy oraz wyeliminowaniu ze składu płuczki polimerów długołańcuchowych można uznać za mało prawdopodobne wystąpienie uszkodzenia strefy złożowej spowodowanego pęcznieniem lepiszcza ilastego, migracją filtratu w głąb skały czy też zanieczyszczeniem skały cząstkami fazy stałej. Badania wykazały, że opracowana płuczka po udoskonaleniu receptury i wykonaniu większej liczby badań porównawczych może znaleźć zastosowanie jako alternatywa dla innych płuczek typu drill-in fluids.
\end{abstract}

Słowa kluczowe: płyn wiertniczy, płuczka mrówczanowa, uszkodzenie strefy przyotworowej, polimer, poliwinyloamina.

ABSTRACT: Making the reservoir ready for production is one of the most important operations when drilling a borehole; therefore, special care should be taken to minimize the impact of any external factors on the reservoir during the drilling. Various mechanisms of formation damage are known. These include mechanical, biological, thermal, but also physicochemical interactions, including the negative effects of drilling fluid, filtrate, and its components. To minimize the damaging effect of the fluid on the permeability of the rock, drill-in fluid is used for drilling through the production zone. The modern oil industry has a number of conceptual solutions for fluid technology used for drilling in. It is possible to adjust the composition and parameters of the fluid, depending on the characteristics of the geological conditions in the borehole. This paper presents the results of research on the technological parameters of a newly developed formate-based mud with the addition of low-molecular-weight polyvinylamine. Work on synthesizing the polymer was carried out in the drilling fluids laboratory of the Drilling, Oil and Gas Department at the AGH University of Science and Technology in Kraków. Based on polyvinylamine and potassium formate, a fluid recipe was designed that is an alternative to typical formate-based muds. For the developed drilling fluid, a number of tests were carried out which involved the examination of rheological, filtration and inhibition properties as well as the impact on damage to the production zone. The research has shown that in addition to good physicochemical properties, the developed mud provides effective protection of the reservoir formation. Thanks to the joint action of formate salt and polyvinylamine together with the elimination of long-chain polymers from the composition of the fluid, damage to the reservoir rock

Autor do korespondencji: M. Stec, e-mail:maciej.stec@exalo.pl

Artykuł nadesłano do Redakcji 20.12.2018 r. Zatwierdzono do druku 15.05.2019 r. 
due to swelling of the clay matrix, filtrate migration into the rock or pore contamination with solid phase particles can be considered as unlikely. The tests have shown that the developed drilling fluid can be used as an alternative to other drill-in fluids as long as it's mixture is improved and more additional comparison tests are performed.

Key words: drilling fluid, formate-based mud, formation damage, polymer, polyvinylamine.

\section{Wstęp}

Efektywne udostępnienie złoża jest jednym z najważniejszych technologicznie wyzwań przemysłu naftowego. Złoże udostępnia się tak, aby zminimalizować szkodliwy wpływ płynu wiertniczego na jego naturalną przepuszczalność. Do dowiercania strefy perspektywicznej używa się płuczek typu drill-in fluid. Jedną z powszechnie stosowanych płuczek do dowiercania jest płuczka na bazie soli organicznych - mrówczanów. Jak wskazuje literatura naukowa i praktyka, płuczkę tę cechuje wiele zalet, jednakże pewne zjawiska wynikające z obecności niektórych komponentów, zwłaszcza polimerów o dużych masach cząsteczkowych, prowadzą do odkładania się tych polimerów, powodując kolmatację porów i wpływając w znacznym stopniu na pogorszenie przepuszczalności w strefie przyotworowej (Civan i Engler, 1994; Iscan, 2006; Al-Yami et al., 2008; Stec, 2017).

\section{Uszkodzenie strefy przyotworowej}

W 1994 roku zdefiniowano pojęcie uszkodzenia strefy przyotworowej jako każdy proces powodujący obniżenie naturalnej przepuszczalności formacji gazowej lub ropnej, a także obniżenie możliwości zatłaczania wody lub gazu do otworu (metody wtórne wydobycia). Uszkodzenie może nastąpić podczas wiercenia, rdzeniowania, zbrojenia otworu, eksploatacji, rekonstrukcji, a także na skutek realizacji wtórnych metod intensyfikacji wydobycia (Civan i Engler, 1994; Iscan, 2006). Zjawisko to powoduje niejednokrotnie znaczący spadek wydobycia. W wyniku zaburzeń przepływu medium w otworach ropnych i gazowych oraz faktu, że wiele otworów zostaje oddanych do eksploatacji jako otwory z nieorurowaną sekcją złożową, naturalna przepuszczalność formacji narażona jest na uszkodzenie, które może następować na skutek efektu:

- mechanicznego (migracja cząstek frakcji koloidalnej, inwazja fazy stałej, formowanie się emulsji, blokowanie wody złożowej itp.);

- fizykochemicznego (pęcznienie iłów, dezintegracja lepiszcza ilastego, nierozpuszczalne wytrącenia i osady, pozostałości po kwasowaniu itp.);

- biologicznego;

- termicznego (procesy stymulacji termicznej) (Schembre i Kovscek, 2005; Iscan, 2006).

\section{Metodyka badań}

Poniżej opisano metodykę wykonywania badań laboratoryjnych zgodnie z obowiązującymi normami (API 13B-1, PN-EN ISO 10414:2012). W pracy wykonywano szereg badań, m.in. pomiar ciężaru właściwego, właściwości reologicznych, filtracji, badano dezintegrację beleczek iłowych, pęcznienie liniowe łupków i inne (Goc et al., 2013).

\section{Oznaczanie pH}

Oznaczanie pH odbywało się za pomocą pehametru przez zanurzenie w roztworze elektrody pomiarowej i odczyt wartości pH z wyświetlacza.

\section{Pomiar gestości płynu}

Pomiar wykonywany był zgodnie z obowiązującymi normami za pomocą wagi płuczkowej produkcji firmy Baroid. Wynik pomiaru, po uzyskaniu równowagi na ramieniu wagi, odczytujemy ze skali umieszczonej na ramieniu wagi.

\section{Oznaczanie parametrów reologicznych pluczki wiertniczej}

Pomiary przeprowadzano zgodnie z normami polskimi i zagranicznymi za pomocą lepkościomierza o sześciu lub dwunastu zakresach prędkości obrotowych. W celu obliczenia parametrów reologicznych płuczki odczytywano wartości wskazań lepkościomierza przy 600, 300, 200, 100, 6 i 3 obrotach. Dzięki powyższym odczytom określono następujące parametry płuczki:

- lepkość pozorną, $\mathrm{AV}[\mathrm{mPa} \cdot \mathrm{s}]$;

- lepkość plastyczną, PV $[\mathrm{mPa} \cdot \mathrm{s}]$;

- granicę płynięcia, YP [Pa];

- wytrzymałość strukturalną po $10 \mathrm{~s}$ i $10 \mathrm{~min}[\mathrm{~Pa}]$.

\section{Pomiar filtracji pluczki wiertniczej}

Pomiar wykonywano w prasie pod ciśnieniem 0,7 MPa (filtracja API). Wynikiem pomiaru jest objętość filtratu, który uzyskuje się po odsączeniu w prasie. Filtrat zostaje zachowany do dalszych analiz chemicznych. Dodatkowo, celem sprawdzenia stabilności temperaturowej płynu, wykonywano pomiary w specjalnej prasie HTHP, pozwalającej mierzyć filtrację w warunkach podobnych do warunków otworowych, w temperaturze do $260^{\circ} \mathrm{C}$ i ciśnieniu różnicowym 3,5 MPa. W tym przypadku wynikiem testu jest uzyskana objętość filtratu pomnożona przez 2. 


\section{Badanie dezintegracji skały ilasto-lupkowej}

Badania dezintegracji skał ilasto-łupkowych wykonywano przez wstępne kondycjonowanie próbek płuczki z próbkami skały w piecu obrotowym typu roller oven. Sprawdzano działanie inhibitujące płuczki przez poddanie próbek dyspergowaniu w środowisku płuczki wiertniczej, a następnie w środowisku wody. Po zakończeniu kondycjonowania i odsianiu zawartości autoklawów przez sito o średnicy oczek $0,43 \mathrm{~mm}-\mathrm{w}$ obu przypadkach próbki suszy się do stałej masy w temperaturze $105^{\circ} \mathrm{C}$. Wynikiem pomiarów są wartości $P_{1}$ i $P_{2}$ - odpowiednio odzysk próbki po dyspersji w płuczce i w wodzie. Wzory przedstawiono poniżej

Wielkość $P_{1}$, będącą procentowym stosunkiem masy próbki pozostałej po dyspersji w płuczce do masy wyjściowej (odzysk próbki po dyspersji w płuczce), oblicza się ze wzoru:

$$
P_{1}=\frac{m_{p} \cdot 100}{m}[\%]
$$

Wielkość $P_{2}$, będącą procentowym stosunkiem masy próbki pozostałej po dyspersji w wodzie do masy wyjściowej (odzysk próbki po dyspersji w wodzie), oblicza się ze wzoru:

$$
P_{2}=\frac{m_{w} \cdot 100}{m}[\%]
$$

gdzie:

$m$ - masa próbki wyjściowej wziętej do badań [g],

$m_{p}$ - masa próbki pozostałej na sicie po dyspergowaniu

w płuczce i wysuszeniu [g],

$m_{w}$ - masa próbki pozostałej na sicie po dyspergowaniu w wodzie i wysuszeniu $[\mathrm{g}]$.

\section{Badanie pęcznienia tupków}

Badania pęcznienia liniowego wykonywano z użyciem aparatu M4600 HPHT Linear Swell Meter firmy Grace Instrument Co. Aparatura umożliwia przeprowadzenie badania liniowego pęcznienia skał (LST - ang. linear swelling test $) \mathrm{w}$ warunkach wysokiej temperatury $\left(\right.$ do $260^{\circ} \mathrm{C}$ ) i wysokiego ciśnienia (do 13,8 MPa) Pomiar można wykonać zarówno w warunkach statycznych, jak i dynamicznych. Pierwszym etapem badań było przygotowanie tabletek ze sproszkowanej skały za pomocą urządzenia M4600 Dual Core/Wafer Compactor. Próbki sproszkowanej skały, o masie $\sim 11,5 \mathrm{~g}$, umieszczano w celkach tego urządzenia i poddawano działaniu ciśnienia 17,2 MPa przez 60 minut. Otrzymane w ten sposób pastylki wykorzystywano w dalszych badaniach. W kolejnym etapie pastylki wykonane z badanej skały umieszczano w celkach pomiarowych aparatu M4600 HPHT Linear Swell Meter, które następnie umieszczano w badanej cieczy. Badanie pęcznienia prowadzono przez 20 godzin w temperaturze $30^{\circ} \mathrm{C}$ pod ciśnieniem atmosferycznym. Wynikiem pomiaru jest krzywa pęcznienia generowana przez aparaturę.

\section{Badanie przepuszczalności}

Badania utraty przepuszczalności dla gazu przeprowadzono według metodyki opracowanej w INiG - PIB. Do badań użyto próbek piaskowca szydłowieckiego. Badania laboratoryjne uszkodzenia przepuszczalności próbek skały zbiornikowej (piaskowca szydłowieckiego) pod wpływem oddziaływania płuczki wykonano przy użyciu:

- prasy filtracyjnej HTHP (OFI, USA) zmodyfikowanej przez INiG - PIB (pomiary filtracji cieczy wiertniczych przez rdzenie w warunkach statycznych i dynamicznych przy $\Delta p_{\max }=2,8 \mathrm{MPa}$ i $T_{\max }=150^{\circ} \mathrm{C}$ );

- uniwersalnego przepuszczalnościomierza firmy Temco (pomiary przepuszczalności w warunkach złożowych $\Delta p_{\max }=21 \mathrm{MPa}$ i $T_{\max }=150^{\circ} \mathrm{C}$ );

- do oceny grubości zewnętrznego oraz wewnętrznego osadu filtracyjnego użyto aparatu rentgenowskiego RTG Kodak 2200.

Po przygotowaniu próbek do badań przeprowadzono symulację procesu uszkodzenia skały złożowej płuczką wiertniczą. W tym etapie na próbkę skały oddziaływano płuczką, najpierw w warunkach filtracji dynamicznej, następnie w warunkach filtracji statycznej, w obydwu przypadkach rejestrując filtrację przez próbkę skały. Następnie próbkę umieszczano w przepuszczalnościomierzu w celu określenia przepuszczalności końcowej dla gazu oraz oceny utraty (uszkodzenia) przepuszczalności. Współczynnik utraty przepuszczalności WU, zdefiniowany jako procentowy spadek przepuszczalności początkowej próbki po wniknięciu do jej przestrzeni porowej cząstek fazy stałej i filtratu, wyraża się wzorem:

$$
W U=\left(1-\frac{k_{d}}{k_{0}}\right) \cdot 100
$$

gdzie:

$k_{d}$ - przepuszczalność uszkodzonej skały porowatej (po oddziaływaniu na nią cieczą wiertniczą), z uwzględnieniem poprawki Klinkenberga, [mD],

$k_{0}$ - przepuszczalność początkowa (nieuszkodzonej skały porowatej), z uwzględnieniem poprawki Klinkenberga, $[\mathrm{mD}]$.

Uwaga: $1 \mathrm{mD}=0,986923 \cdot 10^{-15} \mathrm{~m}^{2}$

Jeżeli przepuszczalność uszkodzonej skały $k_{d}=0$, to utrata przepuszczalności wynosi 100\%.

W trakcie badań utraty przepuszczalności skał piaskowca pod wpływem oddziaływania płuczki - wykonano również pomiary grubości powstałego osadu filtracyjnego na podstawie analizy zdjęć rentgenowskich próbek wraz z osadem filtracyjnym powstałym na ich czołach po procesie kolmatacji i pozostałym po końcowym pomiarze przepuszczalności. 


\section{Badania laboratoryjne}

W celu sprawdzenia możliwości zaaplikowania niskocząsteczkowej poliwinyloaminy (S006) w płuczkach mrówczanowych opracowano recepturę płuczki (płuczka 31) ujętą w tabeli 1 . Parametry technologiczne pokazano w tabeli 2 .

Tabela 1. Receptura płuczki mrówczanowej (31) z poliwinyloaminą (polimerem S006)

Table 1. Recipe of formate based mud (31) with polyvinylamine (S006 polymer)

\begin{tabular}{|l|c|}
\hline \multicolumn{1}{|c|}{ Komponent } & Koncentracja [\%] \\
\hline \hline HCOOK & 3,00 \\
\hline Skrobia & 1,50 \\
\hline PAC & 0,25 \\
\hline XCD & 0,20 \\
\hline S006 & 1,00 \\
\hline Blokator węglanowy & 10,00 \\
\hline
\end{tabular}

Tabela 2. Parametry technologiczne płuczki mrówczanowej (31) z polimerem S006

Table 2. Technological parameters of formate based mud (31) with polyvinylamine (S006 polymer)

\begin{tabular}{|l|c|}
\hline Gęstość $\left[\mathrm{g} / \mathrm{cm}^{3}\right]$ & 1,14 \\
\hline $\mathrm{PV}[\mathrm{mPa} \cdot \mathrm{s}]$ & 51,0 \\
\hline $\mathrm{AV}[\mathrm{mPa} \cdot \mathrm{s}]$ & 84,5 \\
\hline $\mathrm{YP}[\mathrm{Pa}]$ & 32 \\
\hline Filtracja API $[\mathrm{ml}]$ & 3,2 \\
\hline Filtracja HTHP $\left(150^{\circ} \mathrm{C}\right)[\mathrm{ml}]$ & 12,9 \\
\hline Gel $10 \mathrm{~s} / 10 \mathrm{~min}[\mathrm{~Pa}]$ & $10,0 / 10,6$ \\
\hline $\mathrm{pH}$ & 8,5 \\
\hline Dezintegracja pałeczek iłowych $\mathrm{P}_{1} / \mathrm{P}_{2}[\%]$ & $92,5 / 89,4$ \\
\hline Uszkodzenie przepuszczalności $[\%]$ & 14,4 \\
\hline
\end{tabular}

Na podstawie wyników pomiarów stwierdzono, że płuczka z polimerem S006 charakteryzowała się wysokimi parametrami reologicznymi oraz umiarkowaną wartością wytrzymałości strukturalnej. Płuczka posiadała niską wartość filtracji API oraz HTHP $\mathrm{w}$ temperaturze $150^{\circ} \mathrm{C}$. Zauważono również bardzo dobrą inhibicję łupku eoceńskiego, o czym świadczy wysoka wartość odzysku pałeczek iłowych oraz kształt krzywej pęcznienia, która stabilizuje się na wartości około 6\% (przyrost liniowy próbek łupku) (rys. 1).

Głównym etapem badań było sprawdzenie wpływu płuczki mrówczanowej (nr 31) z polimerem S006 na uszkodzenie strefy przyotworowej. W tym celu próbka płuczki została poddana badaniom wpływu na zmianę przepuszczalności pierwotnej próbek piaskowca szydłowieckiego. Na rysunkach 2-4 zestawiono wyniki pomiarów filtracji, grubości zewnętrznego osadu

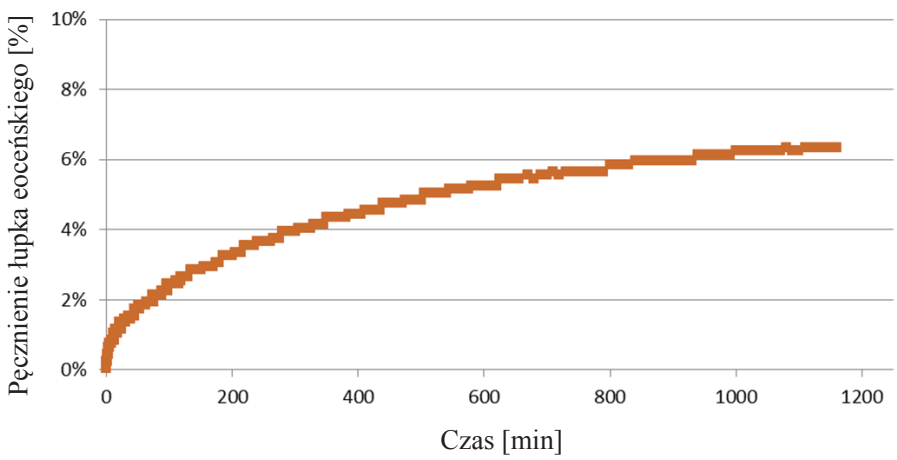

Rys. 1. Pęcznienie łupku eoceńskiego w badanej płuczce z polimerem S006 - wykres wygenerowany przez aparaturę urządzenia HPHT Swell Meter

Fig. 1. Swelling of the Eocene shale in the tested mud with S006 polymer - a graph generated by HPHT Swell Meter unit

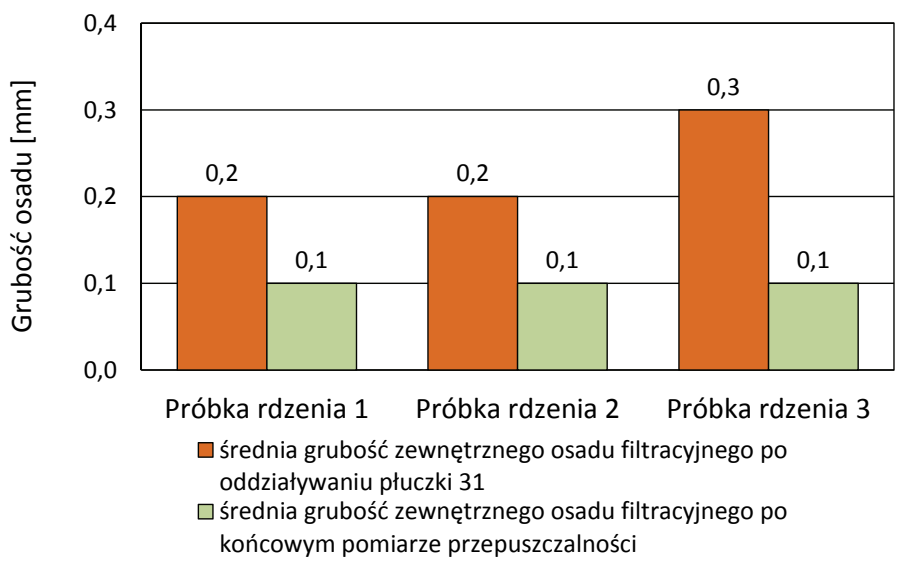

Rys. 2. Porównanie grubości osadu filtracyjnego na powierzchni czołowej próbek rdzeni piaskowca szydłowieckiego po oddziaływaniu płuczki mrówczanowej z polimerem S006 (nr 31) i po końcowym pomiarze przepuszczalności

Fig. 2. Comparison of the filter cake thickness on the face of the samples of the Szydlowiec sandstone cores after impact of the formate based mud with S006 polymer (No. 31) and after the final measurement of permeability

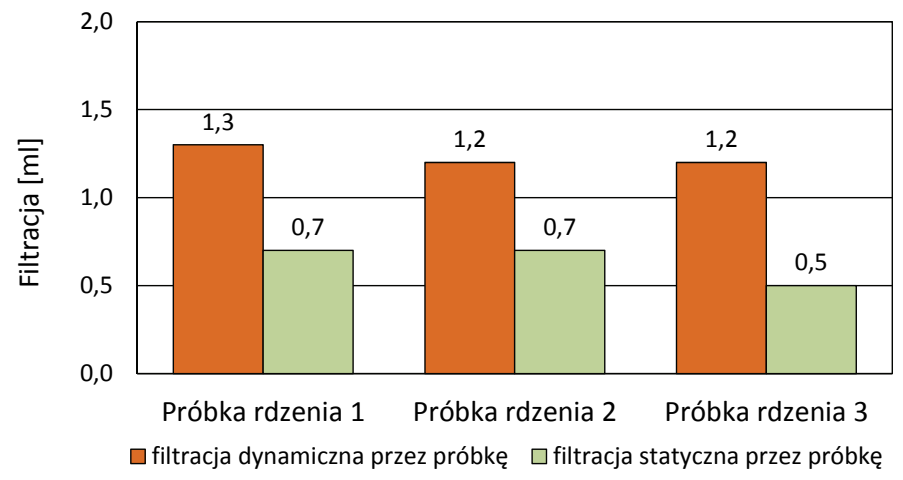

Rys. 3. Porównanie filtracji statycznej i dynamicznej przez próbki rdzeni piaskowca szydłowieckiego podczas oddziaływania płuczką mrówczanową z polimerem S006 (płuczka 31)

Fig. 3. Comparison of static and dynamic filtration through the samples of the Szydlowiec sandstone cores during the interaction with a formate based mud with S006 polymer (mud 31) 


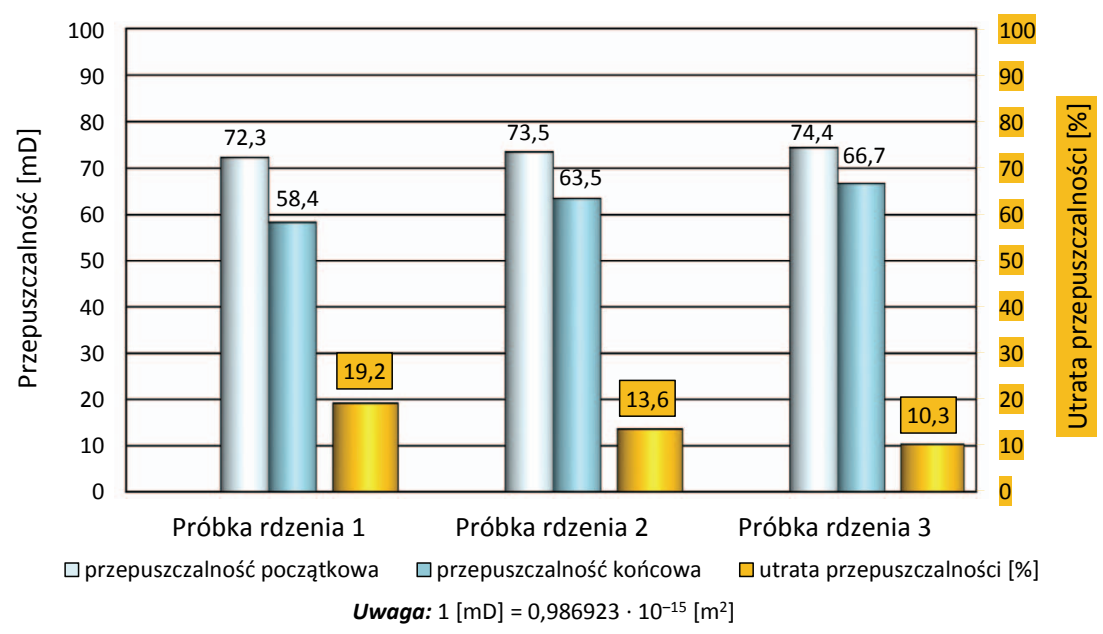

Rys. 4. Porównanie wartości przepuszczalności początkowej i końcowej oraz uszkodzenia przepuszczalności w próbkach rdzeni piaskowca szydłowieckiego po oddziaływaniu płuczką mrówczanową z polimerem S006 (płuczka 31)

Fig. 4. Comparison of initial and final permeability and formation damage in samples of the Szydlowiec sandstone cores after interaction with a formate based mud with S006 polymer (mud 31) filtracyjnego na powierzchni czołowej próbki po oddziaływaniu płuczką i po końcowym pomiarze przepuszczalności oraz badania uszkodzenia przepuszczalności rdzenia piaskowca na skutek oddziaływania płuczką.

Na podstawie badań stwierdzono, że wartości filtracji w warunkach dynamicznych i statycznych we wszystkich próbkach rdzeni piaskowca szydłowieckiego utrzymywały się na niskim poziomie. Grubość zewnętrznego osadu filtracyjnego po kolmatacji oraz po końcowym pomiarze przepuszczalności była bardzo mała. Końcowe wartości przepuszczalności dla gazu są mniejsze od wartości początkowych. Wartość procentowa utraty przepuszczalności nie przekracza jednak $20 \%$.

W następnej kolejności zbadano jakość osadu filtracyjnego po kolmatacji próbek rdzeni piaskowca szydłowieckiego płuczką oraz po pomiarze przepuszczalności końcowej. Wykonano również zdjęcia aparatem rentgenowskim. Zdjęcia pokazano na rysunkach 5 i 6 .
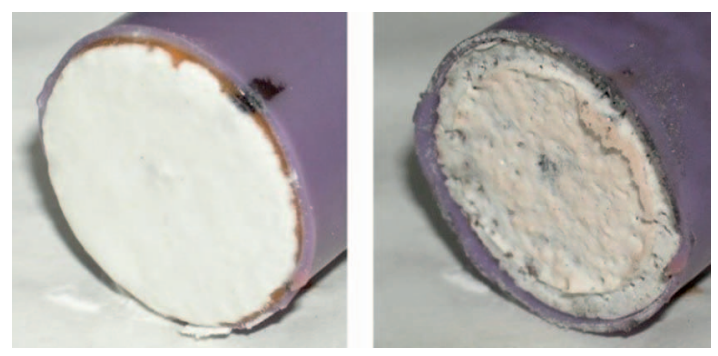

Rys. 5. Osad filtracyjny na powierzchni czołowej próbki po oddziaływaniu płuczką mrówczanową z polimerem S006 (31) i po końcowym pomiarze przepuszczalności (z prawej)

Fig. 5. Filter cake on the sample face after interaction with a formate based mud with S006 polymer (31) and after final permeability measurement (right)

Zaobserwowano cienki, elastyczny osad filtracyjny o małej grubości $(0,2-0,3 \mathrm{~mm})$, który nie został całkowicie usunięty z czoła próbek rdzeni w trakcie symulacji etapu eksploatacji otworu. Pozostały osad nie był grubszy niż $0,1 \mathrm{~mm}$. Zdjęcia wykonane aparatem rentgenowskim pokazywały zasięg kolmatacji
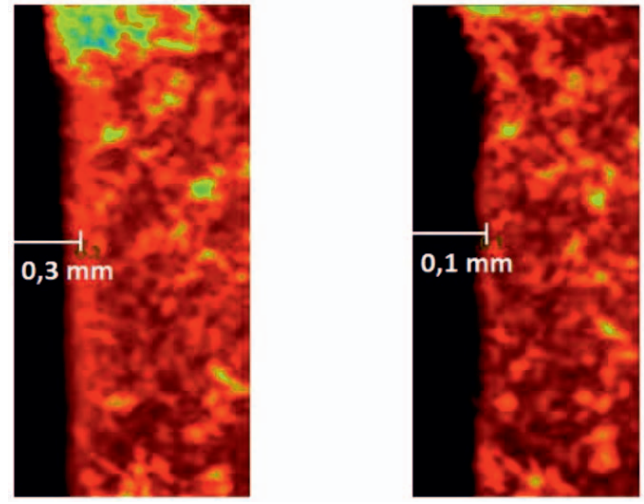

Rys. 6. Zdjęcia rentgenowskie próbki z osadem filtracyjnym po oddziaływaniu płuczką z polimerem S006 (31) i po końcowym pomiarze przepuszczalności (z prawej)

Fig. 6. X-ray images of the sample with the filter cake after exposure to the mud with S006 polymer (31) and after the final measurement of permeability (right)

piaskowca fazą stałą pochodzącą z płuczki. Niebiesko-zielone przebarwienia na zdjęciach przedstawiają filtrat pochodzący z płuczki. Nie stwierdzono obecności wewnętrznego osadu filtracyjnego. Maksymalny zasięg kolmatacji próbki piaskowca wyniósł około $0,08 \mathrm{~mm}$.

\section{Podsumowanie}

Płuczka z niskocząsteczkową poliwinyloaminą wykazała dobre właściwości reologiczne, stabilną filtrację w podwyższonej temperaturze $\left(150^{\circ} \mathrm{C}\right)$ oraz bardzo dobrą inhibicję pęcznienia iłów. Ważną właściwością polimeru S006 jest jego biodegradowalność (Wysocki et al., 2007). W celu określenia struktury i właściwości chemicznych polimeru materiał został zbadany w laboratorium firmy Clariant w Niemczech. Testy na aparaturze GPC (ang. gel permeation chromatography) nie wykazały struktury typowej dla polimerów, potwierdzając tym samym masę molekularną poniżej 25000 u. Stwierdzono, że 
komponent składa się z krótkich łańcuchów polimerowych, co stanowi jego główną zaletę.

Przeprowadzone badania potwierdziły możliwość zastosowania polimeru S006 w technologii płuczek wiertniczych. Dzięki dobrym właściwościom inhibicyjnym występuje ograniczone prawdopodobieństwo uszkodzenia przepuszczalności spowodowanego pęcznieniem lepiszcza ilastego czy też migracją koloidalnej frakcji ilastej wewnątrz porów. Płuczka, ze względu na niską zawartość fazy stałej, ogranicza do minimum możliwość wystąpienia uszkodzenia przepuszczalności spowodowanego przez migrację fazy stałej z płuczki wiertniczej. Dodatkowym czynnikiem minimalizującym to zjawisko jest niska filtracja. Badania udowodniły, że stopień uszkodzenia przepuszczalności jest stosunkowo niewielki. Wynika to między innymi z zastosowania w recepturze płuczki krótkołańcuchowej poliwinyloaminy, charakteryzującej się niską energią adsorpcji na ścianie otworu oraz możliwością tworzenia mniejszych pętli, co oznacza mniejszy wpływ na uszkodzenie strefy przyotworowej (Stec, 2017). Opracowana płuczka wykazuje synergiczne działanie mrówczanu potasu z niskocząsteczkową poliwinyloaminą, zapewniając skuteczną ochronę strefy przyotworowej.

Artykuł został opracowany na podstawie referatu wygłoszonego na Międzynarodowej Konferencji Naukowo-Technicznej GEOPETROL 2018 pt.: Rozwój technik poszukiwania i eksploatacji złóż węglowodorów. Zakopane-Kościelisko, 17-20.09.2018 r.

\section{Literatura}

Al-Yami A.S., Nasr-El-Din H., Bataweel M.A., Al-Majed A.A., Menouar H., 2008. Formation damage induced by various waterbased fluids used to drill HP/HT wells. Society of Petroleum Engineers. DOI: 10.2118/112421-MS.
Civan F., Engler T., 1994. Drilling mud filtrate invasion - improved model solution. Journal of Petroleum Science and Engineering, 11: 183-193.

Goc A., Obuch Z., Wojtasiak P., 2013. Analiza chemiczna płynu wiertniczego i jego filtratu. Instrukcja wewnętrzna Exalo Drilling S.A.

Iscan A., 2006. Experimental and numerical investigation of formation damage caused by water-based drilling fluids. PHD Thesis. Graduate School of Natural and Applied Sciences, Middle East Technical University.

Schembre J.M., Kovscek A.R., 2005. Mechanism of formation damage at elevated temperature. J. Energy Resour. Technol., 127(3): 171-180. DOI: 10.1115/1.1924398.

Stec M., 2017. Opracowanie nowych receptur płuczek mrówczanowych w aspekcie ograniczenia uszkodzenia strefy przyotworowej. Praca doktorska. Wydział Wiertnictwa, Nafty i Gazu Akademii Górniczo-Hutniczej w Krakowie.

Wysocki S., Bielewicz D., Wysocka M., 2007. Badania laboratoryjne nowo opracowanych beziłowych płuczek kationowo-skrobiowych przeznaczonych do przewiercania skał ilastych. Wiertnictwo, Nafta, Gaz, 24(2): 943-954.

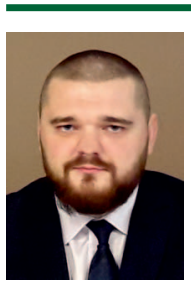

Dr inż. Maciej STEC

Kierownik Działu Badań i Rozwoju

Exalo Drilling S.A.

ul. Naftowa 3

65-705 Zielona Góra

E-mail:maciej.stec@exalo.pl

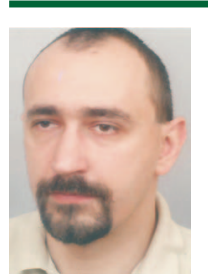

Dr Sławomir WYSOCKI

Adiunkt na Wydziale Wiertnictwa, Nafty i Gazu.

Akademia Górniczo-Hutnicza im. Stanisława Staszica al. Mickiewicza 30

30-059 Kraków

E-mail:swysocki@agh.edu.pl 